FABRICATION AND CHARACTERIZATION OF FAST IGNITION TARGETS

\author{
by \\ D.W. HILL, E. CASTILLO, K.C. CHEN, S.E. GRANT, \\ A.L. GREENWOOD, J.L. KAAE, A. NIKROO, \\ S.P. PAGUIO, C. SHEARER, J.N, SMITH, JR., \\ R.B. STEPHENS, D.A. STEINMAN, and J. WALL
}




\section{DISCLAIMER}

This report was prepared as an account of work sponsored by an agency of the United States Government. Neither the United States Government nor any agency thereof, nor any of their employees, makes any warranty, express or implied, or assumes any legal liability or responsibility for the accuracy, completeness, or usefulness of any information, apparatus, product, or process disclosed, or represents that its use would not infringe privately owned rights. Reference herein to any specific commercial product, process, or service by trade name, trademark, manufacturer, or otherwise, does not necessarily constitute or imply its endorsement, recommendation, or favoring by the United States Government or any agency thereof. The views and opinions of authors expressed herein do not necessarily state or reflect those of the United States Government or any agency thereof. 
GA-A24443

\title{
FABRICATION AND CHARACTERIZATION OF FAST IGNITION TARGETS
}

\author{
by \\ D.W. HILL, E. CASTILLO, K.C. CHEN, S.E. GRANT, \\ A.L. GREENWOOD, J.L. KAAE, A. NIKROO, \\ S.P. PAGUIO, C. SHEARER, J.N, SMITH, JR., \\ R.B. STEPHENS, D.A. STEINMAN, and J. WALL
}

This is a preprint of a paper presented at the 15th Target Fabricartion Specialists Meeting, Gleneden Beach, Oregon, June 1-5, 2003 and to be published in Fusion Science and Technology.

\author{
Work supported by \\ the U.S. Department of Energy \\ under Contract No. DE-FC03-92SF19460
}




\title{
FABRICATION AND CHARACTERIZATION OF FAST IGNITION TARGETS
}

\author{
D.W. Hill, E. Castillo, K.C. Chen, S.E. Grant, A.L. Greenwood, J.L. Kaae, A. Nikroo, S.P. Paguio, C. Shearer, J.N. Smith, Jr., \\ R.B. Stephens, D.A. Steinman, and J. Wall \\ email: dale.hill@gat.com
}

General Atomics, P.O. Box 85608, San Diego, California 92186-5608

Fast ignition is a novel scheme for achieving laser fusion. A class of these targets involves cone mounted $\mathrm{CH}$ shells. We have been fabricating such targets with shells with a wide variety of diameters and wall thicknesses for several years at General Atomics. In addition, recently such shells were needed for implosion experiments at Laboratory for Laser Energetics (LLE) that for the first time were required to be gas retentive. Fabrication of these targets requires producing appropriate cones and shells, assembling the targets, and characterization of the assembled targets. The cones are produced using micromachining and plating techniques. The shells are fabricated using the depolymerizable mandrel technique followed by micromachining a hole for the cone. The cone and the shell then need to be assembled properly for gas retention and precisely in order to position the cone tip at the desired position within the shell. Both are critical for the fast ignition experiments. The presence of the cone in the shell creates new challenges in characterization of the assembled targets. Finally, for targets requiring a gas fill, the cone-shell assembly needs to be tested for gas retention and proper strength at the glue joint. This paper presents an overview of the developmental efforts and technical issues addressed during the fabrication of fast ignition targets.

\section{INTRODUCTION}

The objective of the fast ignition experiments is to explore the possibility of providing the ignition spark using a ultra-short high intensity laser pulse after the fuel has been properly assembled using a traditional compression laser. The challenge is getting this light pulse or electrons produced by it through to the center of the compressed fuel. One current method being explored to accomplish this involves using a massive cone, such as a gold cone to keep the path of the ignition pulse open to the core of the shell with the tip of the cone inserted near the center of the shell. A current series of experiments requires such conemounted shells to investigate the compression of such shells compared to freestanding shells.

We have been producing fast ignition targets in our laboratory for a number of years. Fabrication of these targets requires fabrication of cones and shells of proper dimensions, machining precise holes in the shells for inserting the cones, and precision assembly of the shells onto the cones. Due to the number of steps involved in fabrication such targets, fabrication of the cones and shells is carried out during the same time period so that both parts are ready to be glued together at about the same time. The fabrication of the cones will be discussed first, followed by the fabrication of the shells and then finally the assembly of the targets. Characterization is required during all phases of the process and will be discussed as appropriate. Also, for the recent targets needed for LLE experiments, testing of gas retentiveness and strength of the glue joint of the final assembled is discussed.

\section{FABRICATION OF THE CONES}

The initial step in fabricating the cones is machining a copper mandrel that matches the interior dimensions of the final cone. The copper mandrels are then coated with gold to a thickness greater than the maximum wall thickness specified for the cone. The walls of some of the cones have had a tapered wall thickness. Recent cones are thicker outside the shell than inside to provide handling support and a shelf for precision positioning of the shell.

Figures 1 and 2 illustrate the reasons for this shelf. Figure 1 illustrates the problems associated with aligning a shell on a cone without a shelf. Initially, the angle of the hole in the shell was machined to match the angle of the wall of the cone. However, the wall of the shell was thin and flexible relative to the size of the shell and cone so it 


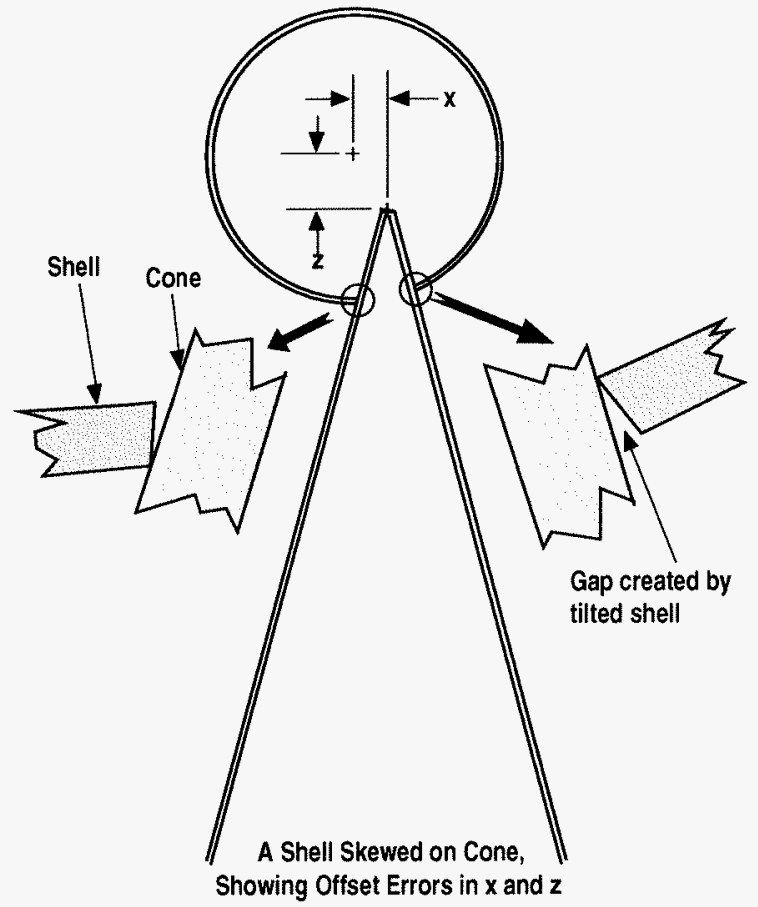

Fig. 1. A cone machined without mounting shelf for the shell, can lead to skewed mounting of the shell as shown in the figure. This makes assembly very difficult and unreliable.

could not provide stable alignment of the center of the shell with the axis of the cone. If this alignment was slightly skewed, the horizontal offset $(x)$ between the center of the

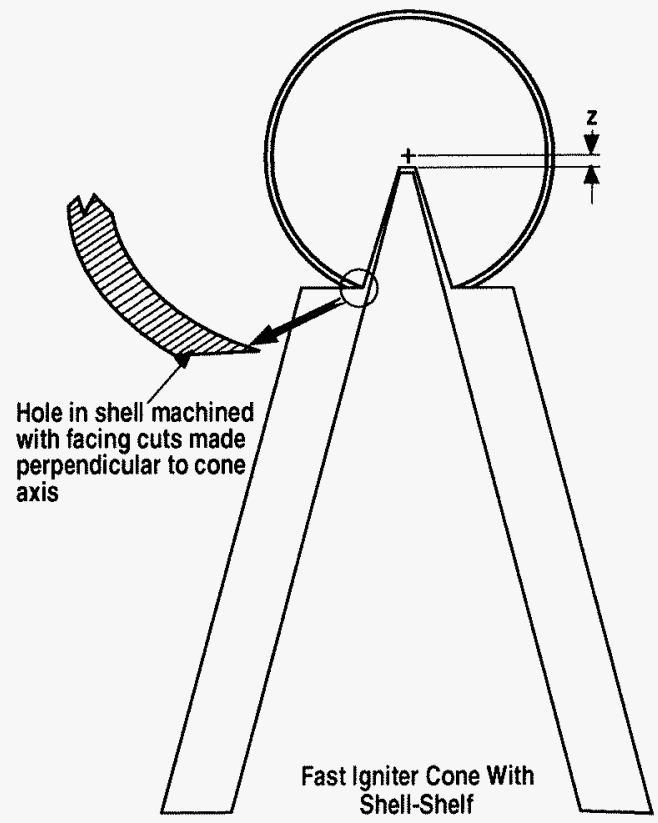

Fig. 2. The use of a shelf on the cone allows precise alignment of the cone tip within the shell by simply using shells with holes machined in the correct position. This leads to much more reliable assembly of parts. shell and the axis of the cone became much greater than specified allowance. Also very small changes in the diameter of the hole were critical because they caused larger than acceptable variations in the vertical offset $(z)$ between the center of the shell and the tip of the cone. Typical requirements are $x=0 \pm 5 \mu \mathrm{m}$ and $z=40 \pm 10 \mu \mathrm{m}$. The alignment problems could be mitigated somewhat by careful positioning during the gluing process, but this process was very time consuming and unreliable.

Figure 2 shows that a wide shelf on the cone provides positioning flexibility to accommodate variations in hole diameter, shell wall thickness, and shell diameter. The shelf provides a fixed penetration distance for the tip into the shell making it easier to match the intended vertical offset by simply controlling the position of the machined hole in the shell. The shelf also provides a wide base for good glue contact and a strong seal for handling and gas retention.

The next step involves back machining the gold coating to the desired shape and thickness. In addition to the steps and tapers in the sides, the cones have had a variety of shapes for the tip, including pointed, hyperbolic, and flat. The final step involves etching the copper mandrel with nitric acid to leave the gold cone. The finished cones are examined under a microscope to insure proper finish and complete removal of the mandrel. Figure 3 is a scanning electron microscope image of a cone, showing the relative size of the flat tip and width of the shelf. This particular cone had a flaw at the tip and therefore was a reject. All cone tips were examined to select only ones without defects at the tip.

\section{FABRICATION OF THE SHELLS}

The depolymerizable mandrel technique, more often referred to as the PAMS-GDP technique was first used by Letts, et. $a l .^{1}$ for ICF capsule fabrication. The current technique used at General Atomics in production mode is detailed by Nikroo, et. al. $^{2}$. Using this technique, we have made capsules with diameters in the 0.4 to $1 \mathrm{~mm}$ range and

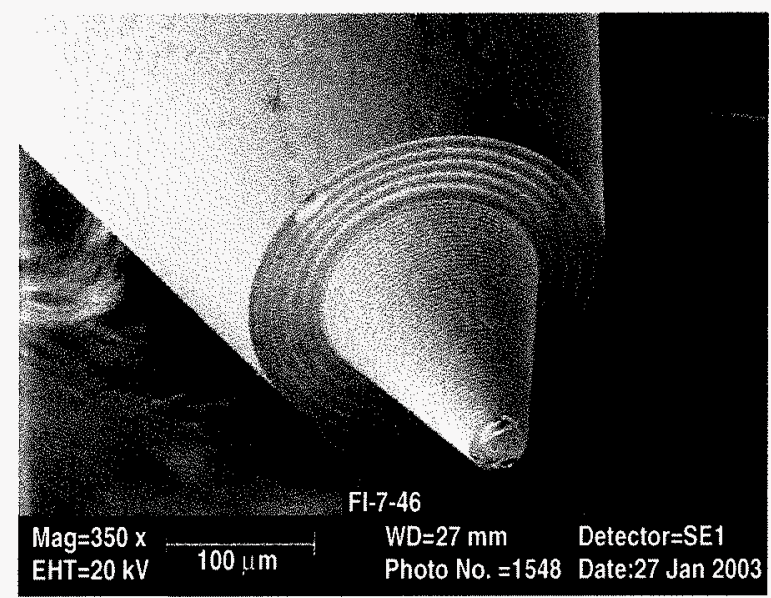

Fig. 3. SEM picture of a cone with a machined flat tip and a shell mounting shelf. This cone has a defect at the very tip and was discarded. 
wall thicknesses of 3 to $60 \mu \mathrm{m}$ for fast ignition targets. The capsules made using this technique for LLE were typically $\sim 900 \mu \mathrm{m}$ in diameter and $24 \mu \mathrm{m}$ in wall thickness which is the standard LLE size. The shells are characterized with regard to sphericity, diameter, wall thickness, and wall uniformity using the methods detailed by Hoppe, et. al. ${ }^{3}$ and visually examined at high magnification for defects. After fabrication of the capsules, a hole needs to be machined in the $\mathrm{CH}$ shells. A small glass slide is used to provide a rigid flat surface for mounting the shells for machining. The shells are typically attached to the slides using fingernail polish. The top of the shells is milled off to create a hole and a flat surface which rests on the cone shelf. The shells are removed from the slide and usually cleaned to remove any residual milling debris. For LLE type shells the $\mathrm{CH}$ shells are strong enough for the machining process. However, for other experiments thinner shells are commonly not rigid enough for the machining process. In those cases, the PAMS mandrel is left in the shell during the machining process to provide the required rigidity. It is removed after the machining step. After the final machined shell is obtained (Fig. 4), its outer diameter and sphericity are measured by shadowgraphy to ensure that there has not been any major dimensional changes of the shell during machining. The hole diameter and location is also measured to ensure that the cone tip will be in the correct position.

\section{ASSEMBLING THE FINAL TARGET}

Shell and cone pairs are then chosen such that the diameter of the hole in the shell closely matches the diameter of the cone at the height of the shelf. The hole must be at least as large as the cone diameter or larger in order to prevent skewing of the center of the shell with

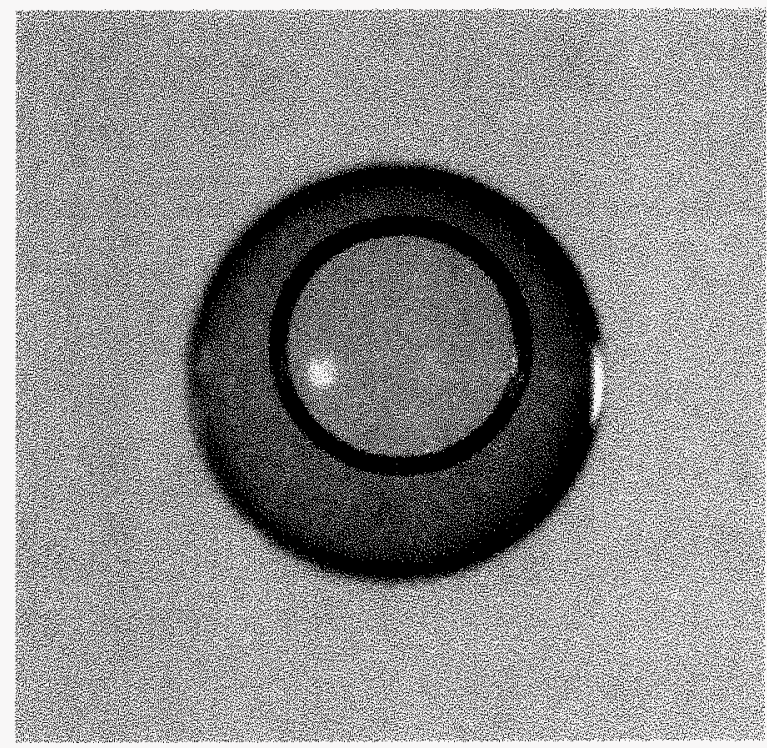

Fig. 4. A CH shell, $\sim 900 \mu \mathrm{m}$ in diameter and $\sim 24 \mu \mathrm{m}$ in thickness after a hole of the proper size is machined into it. respect to the axis of the cone. Using a shell with a substantially larger diameter hole is acceptable as long as the hole is smaller than the shelf, but aligning a shell with an extra large hole with the axis of the cone is generally more time consuming. The diameter of the shell must also be matched to the distance from the cone shelf to the cone tip to ensure proper vertical offset between the cone tip and the center of the shell.

The shell is attached to the cone using UV cure glue. The glue is not initially fully cured with UV light so that the position of the cone center can be checked for correct positioning. If the position is incorrect the shell is gently nudged into the correct position. If the target does not need to be gas tight, it is complete when this glue is cured. However, for the gas tight targets for LLE, a new bead of glue is placed around the joint to assure complete coverage and then it is fully cured with UV light. A fully assembled gas tight target is shown in Fig. 5.

\section{CHARACTERIZING THE FINAL TARGET}

An automated Nikon NEXIV microscope is used to measure the horizontal offset between the center of the shell and the tip of the cone. The target is placed cone down on a glass block on the stage. The origin of the $x-y$ coordinates for the motorized stage is set to the center of the tip of the cone. Bottom lighting is not effective for determining the location of the shell wall because of the shadow from the cone base. Top lighting is not much better because the light scatters off the sides of the cone and the shell wall is very difficult to see. The ring light on the NEXIV microscope is very helpful in this case since it moves down around the target and the light is coming from the side. As Fig. 6 shows, this lighting does a very good job of highlighting the shell wall. The software for the microscope uses the change in contrast to automatically focus on the shell wall and to determine the shell center and thus its horizontal offset from the tip.

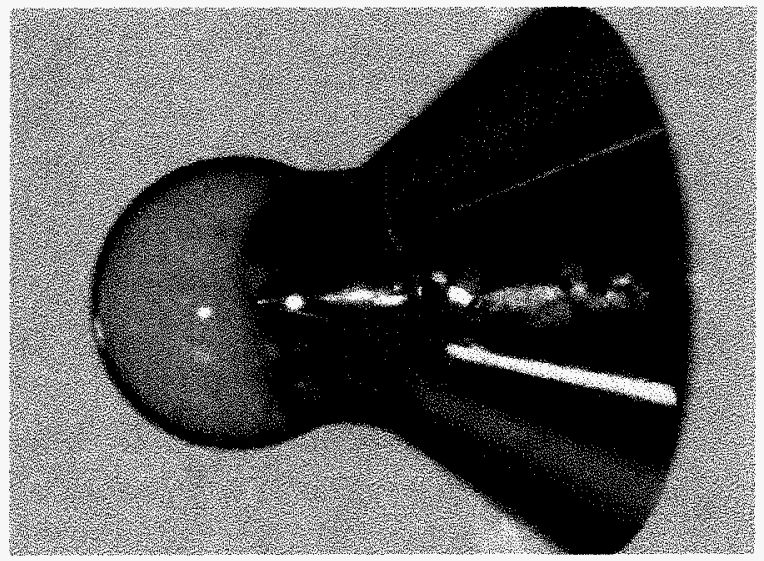

Fig. 5. A completed cone mounted shell assembly for LLE with extra glue applied to the cone-shell joint to ensure gas retention within the $\sim 900 \mu \mathrm{m}$ diameter shell. 


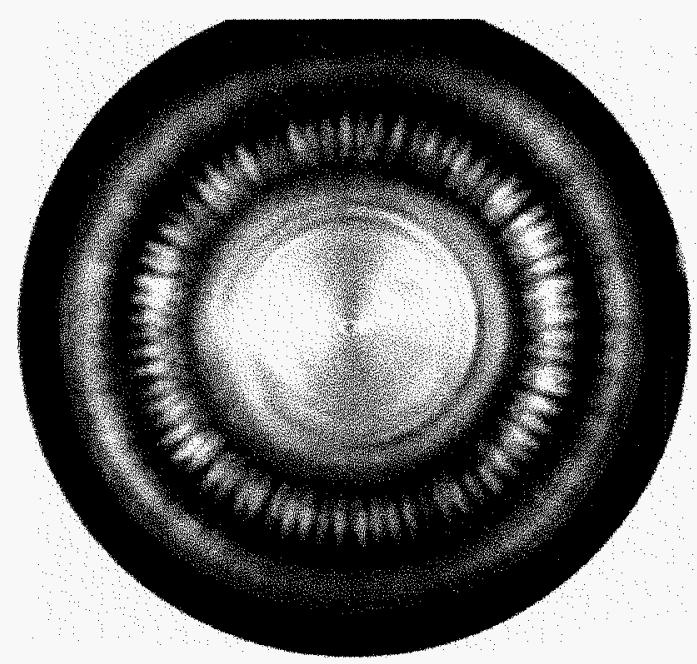

Fig. 6. The side lighting feature of the Nikon microscope is used to find the proper outline of a $\sim 900 \mu \mathrm{m}$ diameter shell when mounted on the cone. The presence of the cone does not allow shadowgraphy by bottom or top lighting.

Unfortunately, the error in manually determining the focus height for the tip of the cone on the NEXIV microscope is of the order of $\pm 2 \mu \mathrm{m}$ which is not acceptable for measuring the vertical offset between the center of the shell and the tip of the cone. Thus, an interferometer is used to measure this offset.

\section{PRESSURE TESTING THE FINAL TARGET}

Pressure testing is performed for those targets that are requested to be gas tight. Several targets are placed in a plastic holder, which is in turn placed in a pressure chamber with view ports on the top and bottom. The chamber is lit from the bottom and viewed from the top with a video camera and attached zoom lens, which monitors the status of the targets. Argon gas is used to ramp up the pressure in the chamber at between 5 and 10 psi per minute to the requested test pressure. The Argon pressure is retained at that level for up to $5 \mathrm{~h}$ to allow the gas to equilibrate to the same pressure inside the shell. At that point, the gas pressure is released to atmospheric pressure in less than $1 \mathrm{~s}$ and the targets monitored for integrity. Whole targets are quickly analyzed by $x$-ray fluorescence measurement under vacuum to assure that they continued argon and to determine the argon half-life by multiple measurements over time.

\section{CONCLUSION}

GA has successfully produced several types of fast ignition targets during the past few years. These targets have included shells with standard GDP walls as well as doped GDP walls. The shell walls have varied between 3 and $60 \mu \mathrm{m}$ thick. The shell outer diameters have varied between 0.4 and $1 \mathrm{~mm}$. Some of the cones have been wide and short while others have been tall and narrow. The cone tips have varied from pointed, to flat, to hyperbolic in shape. However, in all cases, quality targets have been produced in proper quantity and within a proper time frame. GA is also continuing to develop and improve the methods used for fabricating the cones, shells, and final targets.

\section{ACKNOWLEGMENT}

Work supported by the University of Rochester under Contract 412164-G.

\section{REFERENCES}

1. S.A. LETTS, E. M. FEARON, S. R. BUCKLEY, M.D. SACULA, L. M. ALLISON, R.C. COOK, "Preparation of Hollow ICF Targets Using a Depolymerizable Mandrel," Mat. Res. Soc. Symp. Proc. 372125 (1995).

2. A. NIKROO, F.H. ELSNER, D.G. CZECHOWICZ, S.E. GRANT, A.L. GREENWOOD, M.L. HOPPE, B.W. MCQUILLAN, W.J. MILLER, J.M. PONTELANDOLFO, D.A. STEINMAN, R.B. STEPHENS, K.R. SCHULTZ, M. TAKAGI, "Capsule Production and Development For ICF Experiments," Proc. of the First Inertial Fusion Sciences and Application Symposium, Bordeaux, France (2001), Elsevier press.

3. PROJECT STAFF, M.L. HOPPE, Editor, Inertial Confinement Fusion Target Component Fabrication and Technology Development Support, Annual Report to the US DOE, GA-A22305, UC-712, (October 1994 through September1995). 